\title{
Sudore, lacrimis ac sanguine, libertas ${ }^{(*)}$
}

\section{Benedicto de Siqueira Ferreira.}

Ha um quarto de seculo, a maioria de vós ainda não havia brotado para a vida, em ambiente festivo como este, cheio de luzes e de flores, de esperanças e de alegrias, da Faculdade de Direito de São Paulo, como hoje convosco ocorre, se despedia uma pleiade de jovens, ardentes de entusiasmo, de fé e de patriotismo, prontos para enfrentar as asperezas da vida.

Haviam sido ungidos, como vós acabaes de o ser, sacerdotes do Direito, tendo á illharga, a paraninfar o ato, a trazer-lhes o Adeus da Academia, a explendida e inesquecivel figura de Herculano de Freitas.

Mestre dos mais notaveis, amigo dos mais seguros, augurára á turma porvir dos mais promissores, mas tambem sabriamente a advertira do preço da gloria, no lema que gravára no quadro de formatura: "Per aspera, ad astra."

E o vaticinio cumpriu-se.

Sem querermos estender nossas vistas ás demais esferas onde pode fulgurar o jurista, basta que lancemos os olhares para os doutoraes desta Casa e ali vejamos, ainda unidos pelos elos da amizade academica, Mario Masagão, Ernesto Leme, Honorio Monteiro, Lino Leme, Noé Azevedo, Mota Filho, Vicente de Azevedo e Sinesio Rocha.

Jamais de turma alguma de bachareis, tantos, certamente tangidos pela saudade, com maior ardor se debru-

${ }^{*}$ ) Oração de paraninfo proferida perante a turma de bacharelandos de 1944. 
çaram sobre Codigos e Tratados, se consumiram em noites brancas de vigilia, para ter a suprema honra de voltar, para sempre, para as Arcadas e ali envelhecer ao convivio doce de sua eterna e generosa mocidade.

Mas, - ai, senhores! — não ha brilhante sem jaça: ao lado dos mestres eminentes, colegas de turma que me enchem de orgulho, figura tambem aquele que houvestes por bem eleger - e má escolha fizestes, eu vol-o asseguro para vosso paraninfo.

Eis porque, para mim tem significação especial e profunda o vosso cativante gesto.

Recebo-o como homenagem, embora imerecida, ao comemorar minhas bôdas de prata de jurista e nele vejo mais o carinhoso desejo do discipulo de dar brilho á apagada figura do mestre, para que a jaça como que se esmaeça e tanto não empane o brilho dos demais.

Sou-vos pois grato pela vossa gentileza que me atingio em cheio o coração para ali se aninhar para sempre, ao lado das palavras de vosso brilhante orador que, em sua sinceridade amiga, viu como si minhas fossem, por mero reflexo, virtudes que na realidade são vossas pois ornam a nossa velha Escola: o culto apaixonado do Direito e uma exata noção de civismo, ao lado de bravura de que já destes mostras e de um cavalheirismo jamais desmentido.

Perdoae-me, porem, snrs. Bacharelandos, si ao vos dizer o inolvidavel Adeus, haja recordado o passado mas recordar é viver, e viver com intensidade quando a lembrança que acóde nos leva á nossa juventude academica e aos vultos dos grandes Mestres que nem a Morte tem o poder de apartar de nós.

Recordar é viver . e eu desejo viver convosco, com todas as fibras do meu ser, este supremo instante, que, tão nitidamente separa, para vós, a vida alegre e feliz do bacharelando e o momento em que a Saudade já começa a pungir docemente o coração. 
Perdoae-me, pois, e mais, porque si rasguei as brumas de um passado que já vae tão longe, foi para o ligar ao presente, de lá vos trazendo algo de valioso.

Si fui ao passado, ao São Paulo aldeia com foros de cidade, limitado pelo Triangulo e em que a Tabatinguera era quasi um arrabalde mas onde já luzia o velho casarão do largo de São Francisco, foi para, quasi cursores, ascender o facho da tradição no distico que nos deu Herculano de Freitas e cinzelal-o no vosso quadro, em sua versão moderna, em seu modo de ser que melhor se coaduna com a conturbada epoca em que vivemos:

Per aspera, ad astra.

Sudore, lacrimis ac sanguine, libertas.

Apontam ambos ao jurista o caminho unico para que tenham sabor as suas vitorias.

Mas, si em 1919, deixávamos a Faculdade mal egresso o mundo de uma guerra que poucos sofrimentos e sacrificios na verdade, causou ao Brasil e apenas tenues reflexos teve em nossa Patria, abandonais vós as Arcadas quando maior é o fragor d'a batalha mundial que tambem nos aprisiona com seus inexoraveis tentaculos, quando mais aspero é o troar dos canhões que rouquejam pela liberdade, quando mais altas são as labaredas do imenso e universal incendio, tragica lampada votiva da Democracia.

Era então apenas aspero o caminho de seus sacerdotes, hoje "sudore, lacrimis ac sanguine, libertas" é a anátema que pesa sobre seus cultores.

Conquistarás a liberdade com o suor do teu trabalho, as lagrimas do teu sofrimento, o sangue do teu sacrificio, é a sentença que, sem figuras de retorica, ancentúa o preço desse abençoado pão espiritual.

$\mathrm{E}$, é na conquista deste pão que consiste a gloria do jurista no mundo de hoje. 
Da liberdade sob a egide do Direito, tão grata aos nossos corações de juristas, da liberdade que não é a desordem mas da qual um verdadeiro poeta traçou a radiosa imagem :

"La liberté que j’aime est née avec notre âme

Le jour ou le plus juste a bravé le plus fort."

A liberdade que é o proprio Direito, esta simples abstração em que, como Nicolet, "eu diviso a antitese da mentira, da hipocrisia, da ingratidão, da inveja, da violencia, da opressão venha do alto ou de baixo e, para tudo dizer em uma só palavra, da injustiça, em todos os seus matizes e sob todas as formas; como n'ela eu saudo a moderação, a tolerancia, o respeito aos fracos e a obediencia á lei."

Esta, a liberdade que eu venero e que, no plano do Direito Publico, tem a sua expressão maxima na Demccracia.

É preciso, porém, que nos lembremos que os filosofos e juristas dos povos que gemem sob a barbarie totalitaria, não podendo ofuscar o explendor e a magia da ideia que ó vocabulo representa, procuram deformal-a tal como o artista afastado da verdadeira cultura introduz o cubismo na pintura, o aleijão na escultura, o trovejar na musica, a incoerencia na poesia.

São frutos da mesma arvore selvagem que viceja no campo do transpersonalismo e na qual não se pode enxertar um ramo siquer do rijo carvalho da liberdade que frondeja nos ferteis prados do individualismo, do espiritualismo.

São estas expressões que se dizem artisticas tão falsas como o conceito de Democracia dado por Láun que a julga mesmo compativel com o regimen hitleriano...

Partindo da critica acertada que transforma o sufragio universal em lei da maioria e consequente falta de autonomia da vontade da minoria, e julgando fraca a sanção de 
poder esta se transformar naquela, chegam alguns a declarar a falencia da Democracia, outros a ver em outras notas determinantes o conceito da mesma.

Agem os primeiros aguilhoados pelo orgulho, esquecidos do flagrante contraste entre a fragilidade humana e a perfeição ideal dos conceitos juridicos.

Jamais atingirá o homem o "status optimus", para o qual deve entretanto tender: para mim é a Democracia a tendencia que mais se aproxima do almejado Ideal.

A verdadeira Democracia, não a de LÁun ou aquela de que os do outro grupo, ofuscados pela verdade de que o Fstado é um meio e não um fim, querem guardar apenas o nome chegando a dizer que para que seja democratico um governo basta que o mais absoluto autocráta declare que só visa o bem do Povo.

A Democracia não é nem pode ser um simples biombo atraz do qual se desenvolvem apetites pessoaes; mister se faz que suas notas determinantes coexistam para que ela seja.

Realisa o sufragio universal, pela lei da maioria, a vontade da Nação. Á minoria deve ser assegurada, pela sua representação, a possibilịdade de sua vontade autonoma influir nos negocios publicos.

Exercicio da Soberania realmente pelos três Poderes, autonomos e harmonicos mas fiscaes reciprocos.

Finalmente o respeito á dignidade do homem, á opinião publica, livre de se manifestar em reuniões, na praça publica, pela imprensa para que, pela critica elevada dos orgãos do Poder, possa ou retel-os quando caminham para o abismo ou derribal-os nas urnas, sem violencia nem desordem.

Democracia significa sobretudo opinião publica, exclama Nitti, repetindo aliás o pensamento grego para o qual democracia era a ágora, a praça, o comicio; a "ecclesia", a reunião, a assembléa do Povo; e se antecipando ao Sumo 
Pontifice que, no ultimo Natal declarou que "os dois direitos essenciaes dos cidadãos que vivem na democracia são expressar a sua opinião sobre os deveres e sacrificios que lhe são impostos e não serem forçados a obedecer sem primeiro serem ouvidos".

Esta é a Democracia em que eu creio, toda de liberdade e respeito, esta é a democracia incompativel com o Diespotismo que, repudiado pela evolução da humanidade, procura se disfarçar de mil maneiras, sob novos nomes, encoberto por extravagantes misticas e coloridas vestes mas do qual já disse a Marqueza de Alorna, a famosa Alcipe, presa em Chelas, no verdor dos seus dezoito anos, em conhecida ode, tão palpitante de atualidade:

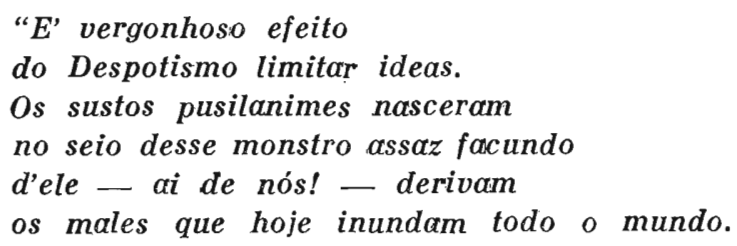

\section{Sweat, tears and blood}

Foi a promessa que fez Winston Churchill ao povo inglês, n'um dos momentos mais angustiosos de sua historia, quando "eram os unicos paladinos ainda em armas em defêsa da causa do mundo".

Notavel foi, porém, a reação da qual se admirou o proprio Chunchill quando, á 8 de Outubro de 1940, declarou á Camara dos Comuns:

"É habito e em muitos casos dever de varios membros da Camara, visitar as zonas destruidas o mais prontamente possivel. Eu mesmo as visito inumeras vezes e nunca fui tratado com tanto carinho como por aqueles que mais sofrem. Parecem gratos por haverem recebido algum beneficio em vez de sangue, suor e lagrimas que, até hoje, foi só o que lhes prometi". 
Admiração não me causam o estoicismo e a bravura do povo inglês mas sim a surpreza manifestada pelo celebrado ministro que melhor que eu deve conhecer as tradições de sua gente e os solidos alicerces em que as mesmas lançam raizes.

Si madrugaram os barões inglêses em bradar: "Habeas corpus", jamais procurou a Inglaterra acorrentar o espirito. de seus filhos.

Notae o contraste: Enquanto na Alemanha escravisada, diz, no Congresso de Nuremberg, o famoso Rudolf Hess, dirigindo-se ao Füherer: "Vós sois a Alemanha, quando praticaes qualquer ato, é a Nação que o pratica, quando julgaes, é a Nação que julga" é a Inglaterra governada pela opinião publica, é ela o proprio Povo.

Eis porque, ainda quando a velha Albion, em dias tristes e cruciantes, permanecia como unico fulcro em defêsa da civilisação, mantendo o fogo sagrado que a ha-de levar á Vitoria, jamais descri do resultado desta guerra.

Póde o trabalho escravo ser produtivo mas o fruto será amargo e jamais terá a alma das cousas vivificadas pelo sopro do artista; póde o escravo se bater pelo Senhor, zurzido pelo latego impiedoso, mas em peleja com o homem consciente e livre, jamais terá a vitoria final: a Inglaterra perdeu inumeras batalhas, nunca uma guerra, pois é a liberdade que conduz os povos á vitoria.

$\mathrm{E}$, enquanto a cultuar, a Grã Bretanha será sempre como a viu Byron:

"the inviolate island of the sage and the free.." a ilha inviolavel do homem prudente e livre.

Suor, lagrimas e sangue..

Trabalhos, sofrimentos e sacrificios.

E o calvario da França aprisionada nesta Bastilha do: seculo XX que era a fortaleza de Hitler, esse vulto que não encarna uma idea mas é a expresșão de um desespero... 
Da França que vive um novo 14 de Julho pois caiu mas não morreu. .

Da França que libertou sua capital, a Cidade Luz, sob os aplausos de toda a humanidade; da França que, tornando real a definição de exercito — a Nação em armas mais uma vez se levanta como um só homem e aos acordes da Marselhêsa forma seus batalhões para derribar o estandarte sangrento da tirania.

Da França que, em nós, seus filhos espirituaes, vive pelos seus filosofos e pensadores, juristas e ecónomos, sabios e artistas; da França, onde se operou a zimase de que surgiu o conceito da Democracia moderna, pela sua Declaração dos Direitos do Homem; da França, enfim, que jamais perecerá enquanto o povo francês, na praça publica, comemorar ruidosa e festivamente, com bailados e musica, as noites de 14 de Julho, n'uma afirmação vigorosa e simbolica, de haver para sempre reivindicado aos Capetos, transformando o absolutismo em liberdade, a confissão enfermiça nos labios de Luiz XIV mas sadia no coração do francês. de que "l'Etat c'est moi"...

\section{Suor, lagrimas e sangue...}

É oriente europeu, onde a Russia, essa gigantesca retorta de alquimia social, ainda prudentemente velada a olhos profanos, turbilhona em reações em busca da pedra filosofal que ha de transformar em aurea liberdade a plumbea opressão dos Czares.

Mas engressa de uma infidavel noite de tirania e de ignorancia, a Russia que, na guerra de 1914, era apenas o "rolo compressor", se transforma em potencia, demonstrando que já muito avançou no caminho da liberdade!

Si a compararmos á França revolucionaria, verificarcmos que os mesmos exageros surgem no conhecido movi- 
mento pendular, com maior intensidade e maior duração, porém, pois mais radical é a evolução, iniciando-se, como se iniciou, em verdadeiro ambiente medieval, de que só lentamente o russo póde se libertar como da figura lendaria do Senhor de todas as Russias.

Esta guerra, com seus sofrimentos e sacrificios como catalisadores, abreviará certamente as reações da experiencia comunista e si não a levar á abolição do Estado, conduzil-a-hă á sua amenisação pela Democracia, pedra filosofal que tanto busca...

Suor, lagrimas e sangue.

Significa a trilha dolorosa que a America se impoz para salvar nossa civilisação e pagar uma divida de honra.

A America não é, diz NitTr, uma nova civilisação mas uma nova Europa.

De lá nos veio, para o fertil sólo americano, embarcada no May Flower, a semente da Democracia.

Mas, si na Europa, na segunda metade do seculo XVIII, não havia ainda nem republicanos nem democratas, mas sim predominava a idéa que nenhuma republica podia existir sinão em pequenos grupos, como na Antiguidade; si na França de 89 havia tão sómente espiritos sedentos de liberdade que aspiravam apenas por uma monarquia constitucional, nos moldes da inglêsa: si Mirabead, no primeiro periodo da revolução não falava em republica sinão com horror e escárneo, no solo virgem da America, sem monarcas nem aristocracia, sem privilegios de classes nem velhos e arcaicos conceitos sobre a legitimidade do Poder, a semente germinou fecunda na Declaração de Direitos da Virginia.

Sejam a tradição cristã, Calvino e os protestantes francêses, como querem outros, os Escolasticos, os Enciclopedis- 
tas e mesmo Luthero os precursores da Democracia moderna que teve por muito tempo, como breviario, a obra de Rousseau, na verdade ela se estruturou em terras da America que é pois o seu berço.

"O fato politico fundamental da Historia Moderna, assevera NiTT, foi o movimento americano que se iniciou com a declaração de direitos e culminou atravẹz da declaração da independencia, na Constituição Democratica de 1787. A propria declaração de Direitos do Homem, na França, em 1789, não é sinão uma parafrase desses principios. E, foi só o exemplo americano que, quando chegou a hora critica do conflito entre a monarquia e o terceiro estado, determinou aquele movimento democratico e republicano que da França se espalhou por toda a Europa."

LAFAyETTE, esse marquez indomavel que da França veio para lutar pela causa da independencia americana, foi, no dizer de LÉon BuUM, o agente de ligação entre as duas democracias.

Eis porque, coalhando os mares de barcos e os ares de aviões, partiram os americanos a combater "as ditaduras anti-democraticas que aqui e ali surgiram, na afirmação de Paul Duez, decáno da Faculdade de Direito de Lille, seja abertamente seja em formas lavradas"; eis porque, ao pisar as areias das praias francezas brandaram os soldados americanos:

\section{-_ "Aqui estamos, Lafayette!"}

E, com os Estados Unidos, se levantou a America Latina, tendo na vanguarda o Brasil que já luta em terras d'Italia, abraçando a divisa sangrenta:

Sudore, lacrimis ac sanguine, libertas.

Tragica maldição que pesa tambem sobre nossa Patriạ! 
Fado triste que de nós afasta neste instante Celso Braga, Geraldo de Camargo Vidigal e Rui Pereira de Queiroz que, quebrando a tradição, figuram, pela vez primeira, em quadro de formatura não com a magestade augusta das vestes talares mas com a gloriosa farda do Exercito Nacional, n'uma realisação viril do "Silent leges inter arma".

E a eloquencia de Manlius, a eloquencia de Brutus.

Este, querendo fazer expulsar os Tarquinios de Roma, não se inflama em discurso, não floreia periodos, não rendilha orações, não cinzela frases, não se exalta nem deblatera, não traduz emfim a indignação que lhe borbulha no peito na eloquencia da linguagem, mas levanta em seus braços vigorosos o corpo sangrento de LuCRECIA apunhalada, simbolo de uma mocidade que se imola mas nã̉o se corrompe!

$\mathrm{E}$, este espetaculo é mais emocionante que um discurso, é o triunfo da eloquencia do gesto...

E eloquencia do sangue que jorra, da carne que se dilacera, da fèrida que se abre, da vida que se evola, da vitima que se sacrifica...

E a eloquencia em que o orador amordaça a propria palavra, em que a verdade surge por si mesma e fustiga e flagela, fére e ferretea, castiga e esmaga..

E a eloquencia que o Bronze da Historia regista.

E a eloquencia causticante que vós tão bem conheceis, snrs. Bacharelandos de 1944...

\section{Snrs. Bachareis!}

Tracei-vos a imagem do mundo atual, tão cheio de dores e de sacrificios, de angustias e de incertềsas: vosso campo de batalha como sacerdotes do Direito, paladinos da Liberdade, soldados da Democracia. 
Ide, mas não vos aparteis jamais das Arcadas, deste Convento que, como os medievaes, nos momentos sombrios de nossa nacionalidade, é o guarda incorruptivel de nossas tradições liberaes, tabernaculo onde pulsa o coração da Patria e resplandece a Consciencia Juridica da Nação! Tende sempre os olhos voltados para esta Casa e comungae sempre em seus ideaes; lutae com a serenidade a fé inabalavel do Jurista, a bravura e civismo do Bandeiramente, o patriotismo e a coragem do Brasileiro, o cavalheirismo e a altivez do Latino e a fortaleza de animo e o estoicismo do Cristão.

Com a serenidade e a fé inabalavel do Jurista que, consciente da força do Direito, não se atemorisa com a fereza das paixões. Si a advertencia de Levy Ulmann - A hora é a do Jurista! - não conseguiu deter a humanidade ás bordas do abismó da guerra, certamente ha de confiar á Toga, quando cessar a tarefa destruidora das armas, o imenso trabalho da reconstrução do mundo de amanhã.

Com a bravura e o civismo do Bandeirante que, sem alarde nem auxilio, dilata as fronteiras da Patria e em sua marcha para Oeste, rasga sertões, desbrava a selva virgem, vadeia rios, escala montanhas e apaga da Historia o tratado de Tordesilhas contra o qual em vão clamára um rei - Francisco I, de França - pedindo que lhe mostrassem o testamento de Adão.

Com a coragem e o patriotismo do Brasileiro que, ensaiando ainda os primeiros passos, entra no mundo conhecido de então arrasando a França Antartica e sobre os destroços do forte de Henriville que passará para sempre a se chamar Rio de Janeiro, fazendo "benzer por um bispo, no morro da Gloria, a Igreja da futura capital do Brasil". Com a coragem e patriotismo do Brasileiro que, pacifico por indole, soube sempre de então para cá, haurir na sua incapacidade de ser brutal, a força que mantem a unidade e a dignidade nacionaes, n'uma afirmação que o Brasil é dos brasileiros. 
Com o cavalheirismo e a altivez de um Latino, cavalheirismo que é a lealdade no combate e a generosidade na vitoria, altivez que humanisa a luta e virilisa o vencedor.

Com a fortalesa de animo e o estoicismo do Cristão que, por seus apostolos e pregadores, santos e martires, se alçou das catacumbas de Roma ao poderio universal do Vaticano.

Si lutardes sempre assim, como vindes fazendo, vossos nomes se cobrirão de bençãos e certamente

Esse immenso colosso gigante conseguireis

Erguel-o de pé! 